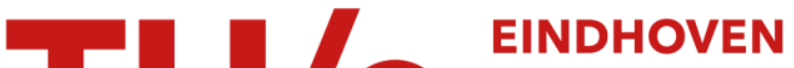 UNIVERSITY OF TECHNOLOGY
}

\section{Hybrid particles derived from alendronate and bioactive glass for treatment of osteoporotic bone defects}

Citation for published version (APA):

Diba, M., Camargo, W. A., Zinkevich, T., Grünewald, A., Detsch, R., Kabiri, Y., Kentgens, A. P. M., Boccaccini, A. R., van den Beucken, J. J. J. P., \& Leeuwenburgh, S. C. G. (2019). Hybrid particles derived from alendronate and bioactive glass for treatment of osteoporotic bone defects. Journal of Materials Chemistry B, 7(5), 796-808. https://doi.org/10.1039/c8tb03062f

\section{Document license:}

TAVERNE

DOI:

10.1039/c8tb03062f

Document status and date:

Published: 07/02/2019

\section{Document Version:}

Publisher's PDF, also known as Version of Record (includes final page, issue and volume numbers)

\section{Please check the document version of this publication:}

- A submitted manuscript is the version of the article upon submission and before peer-review. There can be important differences between the submitted version and the official published version of record. People interested in the research are advised to contact the author for the final version of the publication, or visit the $\mathrm{DOI}$ to the publisher's website.

- The final author version and the galley proof are versions of the publication after peer review.

- The final published version features the final layout of the paper including the volume, issue and page numbers.

Link to publication

\section{General rights}

Copyright and moral rights for the publications made accessible in the public portal are retained by the authors and/or other copyright owners and it is a condition of accessing publications that users recognise and abide by the legal requirements associated with these rights.

- Users may download and print one copy of any publication from the public portal for the purpose of private study or research.

- You may not further distribute the material or use it for any profit-making activity or commercial gain

- You may freely distribute the URL identifying the publication in the public portal.

If the publication is distributed under the terms of Article 25fa of the Dutch Copyright Act, indicated by the "Taverne" license above, please follow below link for the End User Agreement:

www.tue.nl/taverne

Take down policy

If you believe that this document breaches copyright please contact us at:

openaccess@tue.nl

providing details and we will investigate your claim. 
Check for updates

Cite this: J. Mater. Chem. B, 2019, 7, 796

Received 20th November 2018, Accepted 26th December 2018

DOI: $10.1039 / c 8 t b 03062 f$

rsc.li/materials-b

\section{Hybrid particles derived from alendronate and bioactive glass for treatment of osteoporotic bone defects $\dagger$}

\author{
Mani Diba, $\stackrel{\ddagger}{\mathrm{a}}^{\mathrm{a}}$ Winston A. Camargo, $\S^{\mathrm{a}}$ Tatiana Zinkevich, $\S^{\mathrm{b}}$ Alina Grünewald, ${ }^{c}$ \\ Rainer Detsch, ${ }^{C}$ Yoones Kabiri, (iD d Arno P. M. Kentgens, (D) ${ }^{b}$ Aldo R. Boccaccini, ${ }^{c}$ \\ Jeroen J. J. P. van den Beucken ${ }^{a}$ and Sander C. G. Leeuwenburgh (DD*a
}

\begin{abstract}
Osteoporosis is the most widespread metabolic bone disease which represents a major public health burden. Consequently, novel biomaterials with a strong capacity to regenerate osteoporotic bone defects are urgently required. In view of the anti-osteoporotic and osteopromotive efficacy of alendronate and 45S5 bioactive glass, respectively, we investigated the feasibility to synthesize novel hybrid particles by exploiting the strong interactions between these two compounds. Herein, we demonstrate the facile preparation of a novel class of hybrid particles of tunable morphology, chemical composition and structure. These hybrid particles (i) release alendronate and various inorganic elements $(\mathrm{Ca}, \mathrm{Na}, \mathrm{Si}$, and $\mathrm{P})$ in a controlled manner, (ii) exhibit a strong anti-osteoclastic effect in vitro, and (iii) stimulate regeneration of osteoporotic bone in vivo. Consequently, this novel class of hybrid biomaterials opens up new avenues of research on the design of bone substitutes with specific activity to facilitate regeneration of bone defects in osteoporotic patients.
\end{abstract}

\section{Introduction}

Osteoporosis is the most widespread metabolic bone disease which increases the risk of bone fractures considerably by reducing bone mass. ${ }^{1}$ Each year around 9 million osteoporotic bone fractures occur worldwide, ${ }^{2}$ which represents a major public health burden. Biomaterials are frequently applied to support the process of bone healing, but conventional bonesubstituting biomaterials lack the capacity to ensure successful healing of bone suffering from osteoporosis. ${ }^{3,4}$ Consequently, novel biomaterials specifically designed to regenerate osteoporotic bone defects are urgently required. Generally, catabolic processes dominate anabolic processes in osteoporotic bone, which compromises regeneration of bone defects. ${ }^{5}$ Bisphosphonates such

\footnotetext{
${ }^{a}$ Department of Regenerative Biomaterials, Radboud University Medical Center, Philips van Leydenlaan 25, 6525 EX, Nijmegen, The Netherlands. E-mail: Sander.Leeuwenburgh@radboudumc.nl

${ }^{b}$ Institute for Molecules and Materials, Radboud University, Heyendaalseweg 135, 6525 AJ Nijmegen, The Netherlands

${ }^{c}$ Institute of Biomaterials, Department of Materials Science and Engineering, University of Erlangen-Nuremberg, Cauerstraße 6, 91058 Erlangen, Germany

${ }^{d}$ Kavli Institute of Nanoscience Delft, Delft University of Technology,

Van der Maasweg 9, $2629 \mathrm{HZ}$ Delft, The Netherlands

$\dagger$ Electronic supplementary information (ESI) available. See DOI: 10.1039/c8tb03062f \# Current address: Institute for Complex Molecular Systems, Eindhoven University of Technology, P.O. Box 513, $5600 \mathrm{MB}$, Eindhoven, The Netherlands.

$\S$ These authors contributed equally to this work.
}

as alendronate (alendronic acid; ALN) are common anti-catabolic drugs which inhibit osteoclastic bone resorption. ${ }^{6}$ These drugs are usually administered systemically, which results in low bioavailability, a lack of site specificity and increased risks of side effects. A major side effect of such high-dose and long-term bisphosphonate treatment is osteonecrosis of the jaw. ${ }^{7}$ Although bisphosphonates effectively decrease bone resorption, effective stimulation of anabolic bone formation is required to achieve successful regeneration of osteoporotic bone defects. ${ }^{5,8}$ Bioactive glasses (BGs) are typically amorphous calcium-containing silicates which are well-known for their osteopromotive capacity. ${ }^{9,10}$ The most frequently used type of BGs is the 45S5 composition, which contains $45 \mathrm{wt} \% \mathrm{SiO}_{2}, 24.5 \mathrm{wt} \% \mathrm{CaO}, 24.5 \mathrm{wt} \% \mathrm{Na}_{2} \mathrm{O}$, and $6 \mathrm{wt} \%$ $\mathrm{P}_{2} \mathrm{O}_{5}{ }^{9}{ }^{911}$ This type of $\mathrm{BG}$ is osteoconductive, osteogenic, and biodegradable. ${ }^{10,12-14}$ Consequently, in view of the strong antiosteoporotic and osteopromotive capacity of bisphosphonate drugs (such as ALN) and 45S5 BG, respectively, we hypothesize that hybrid formulations of both compounds facilitate highly effective regeneration of defects in osteoporotic bone. Nevertheless, only very few studies investigated the feasibility of combining BGs with bisphosphonate drugs. Srisubut et al. ${ }^{15}$ reported that local delivery of ALN with BG granules (Biogran ${ }^{\circledR}$ ) enhanced the osteopromotive efficacy of BG granules when implanted in mandibular bone defects of healthy rats. Nevertheless, this study did not provide any details on the effects of ALN on the chemical structure of BG granules. Bui et al. ${ }^{16}$ 
developed zoledronate-46S6 BG composites by simple adsorption of zoledronate onto BG particles. In 2011, Lee et al. ${ }^{17}$ reported that osteoblastic differentiation of cells cultured in the presence of a bioactive glass-ceramic was increased when a specific concentration $\left(10^{-7} \mathrm{M}\right)$ of ALN was added to the culture media. In 2013, Rosenqvist et al. ${ }^{18}$ studied the interaction between S53P4 BG with clodronate and reported the formation of a calcium clodronate layer on the BG surface upon mixing of both substances in a saline solution. However, this precipitated layer could not be isolated and its chemical composition was not determined. Other studies have used physical adsorption ${ }^{19}$ or vacuum infiltration ${ }^{20}$ methods to achieve local delivery of bisphosphonate drugs from BG nanoparticles or coatings, respectively. Generally, despite the fact that promising indications have been reported for the strong affinity between BGs and BPs, these interactions have not been studied systematically as basis for the synthesis of a new class of hybrid BG-BP biomaterials.

Herein, we demonstrate the facile preparation of a novel class of hybrid biomaterials by exploiting the strong interaction between ALN and 45S5 BG particles. By immersing BG particles in aqueous ALN solutions at different $\mathrm{pH}$ and ALN/BG ratios, we synthesize hybrid particles of tunable morphology, chemical composition and structure through a carefully controlled precipitation process. By monitoring the precipitation kinetics as a function of immersion time using inductively coupled plasmaoptical emission spectroscopy and solid-state nuclear magnetic resonance spectroscopy, we obtain fundamental understanding of the interactions between BG and ALN and the resulting formation mechanism of hybrid particles. We demonstrate that these hybrid particles (i) release alendronate and various inorganic elements ( $\mathrm{Ca}, \mathrm{Na}, \mathrm{Si}$, and $\mathrm{P}$ ) in a controlled manner, (ii) exhibit a strong anti-osteoclastic effect in vitro, and (iii) stimulate regeneration of osteoporotic bone in vivo. Consequently, we conclude that this novel class of hybrid biomaterials opens up new avenues of research on the design of bone substitutes with specific activity to induce regeneration of bone in osteoporotic patients.

\section{Materials and methods}

\subsection{Materials}

BG particles (45S5 composition) with a mean particle size of $2.0 \pm 1.2 \mu \mathrm{m}$ were obtained from Schott AG (Mainz, Germany). Alendronic acid (4-amino-1-hydroxybutane-1,1-diphosphonic acid) powder was purchased from AK Scientific (Union City, CA, USA). 4-(2-Hydroxyethyl)piperazine-1-ethanesulfonic acid (HEPES; $\geq 99.5 \%$ ) and 2-( $N$-morpholino)ethanesulfonic acid hydrate (MES hydrate; $\geq 99.5 \%$ ) were obtained from SigmaAldrich. Sodium hyaluronate powder (1.01 MDa-1.8 MDa) was purchased from Lifecore Biomedical (Chaska, MN, USA). All other chemicals were reagent grade and used without any purification.

\subsection{Immersion procedure}

Bisphosphonate solutions were prepared by dissolving $100 \mathrm{mM}$ of ALN powder in Milli-Q water and adjusting their $\mathrm{pH}$ using
$\mathrm{NaOH}$ solution. BG particles were immersed in bisphosphonate solutions ( $\mathrm{pH} 5,7$ or 9) at concentrations of 11.5, 23, and $46 \mathrm{mg} \mathrm{mL}{ }^{-1}$ corresponding to $\mathrm{Ca}_{\mathrm{BG}} / \mathrm{ALN}$ molar ratios of 0.5 , 1, and 2, where $\mathrm{Ca}_{\mathrm{BG}}$ and ALN correspond to Ca content of BG particles and ALN molecules in solution, respectively. The mixtures were kept at $37{ }^{\circ} \mathrm{C}$ for various time periods up to three days. Subsequently, the mixtures were centrifuged at $5000 \mathrm{rpm}$ for $5 \mathrm{~min}$. The supernatants were collected for further analysis and the solid sediments were rinsed with Milli-Q water through a redispersion and centrifugation (5000 rpm for $5 \mathrm{~min}$ ) step. Thereafter, the sedimented hybrid particles were dried at $65{ }^{\circ} \mathrm{C}$ for $2 \mathrm{~h}$, after which they were kept at room temperature for further analysis. The composition of hybrid particles in this paper is denoted by $\operatorname{HP} X-Y$, where $X$ and $Y$ indicate the $\mathrm{Ca}_{\mathrm{BG}} / \mathrm{ALN}$ molar ratio and the $\mathrm{pH}$ of bisphosphonate solution used for the immersion procedure, respectively.

\subsection{Electron microscopy}

A Field Emission Scanning Electron Microscope (FE-SEM; Sigma 300, Zeiss, Germany) equipped with an energy-dispersive X-ray detector (EDX; XFlash detector $610 \mathrm{M}$, Brucker Nano $\mathrm{GmbH}$, Germany) was used for morphological evaluation of particles and EDX mapping of Si. For these experiments, sample preparation was carried out by dispersing the particles on a sticky carbon tape and sputter-coating with a conductive chromium layer with a thickness of $\sim 5 \mathrm{~nm}$. The size of hybrid microparticles was determined by measuring the width and length of 50 particles in SEM images.

A Transmission Electron Microscope (TEM; Titan cubed G2 60-300) equipped with an EDX detector was used for scanning transmission electron microscopy (STEM) and EDX mapping of single particles at $300 \mathrm{kV}$. For these experiments, sample preparation was carried out by dispersing $0.02 \mathrm{~g}$ of the particles in $2 \mathrm{~mL}$ of ethanol using a sonication bath ( $5 \mathrm{~min}$ ). Thereafter, $4 \mu \mathrm{L}$ of the dispersion was drop-casted onto a glow-discharged standard perforated carbon TEM grid (Quantifoil ${ }^{\mathbb{R}} 200$ mesh) and incubated for 1 minute. Finally, the TEM grid was rinsed with Milli-Q water, dried and used for the imaging experiments.

\subsection{Elemental analysis}

The ALN content of the precipitated particles was determined by measuring their nitrogen content using a CN Elemental Analyzer (NA1500, Carlo Erba - Thermo Fisher Scientific, USA). Calcium (Ca), sodium (Na), phosphorus (P) and silicon (Si) contents of the precipitated particles were determined by elemental analysis of the supernatants using Inductively Coupled Plasma-Optical Emission Spectrometry (ICP-OES, iCAP 6300, Thermo Fisher Scientific, USA). First, the total mass of each element in the mixture (ALN solution + BG particles) was calculated based on the elemental composition of the ALN solutions and BG particles. Subsequently, the composition of precipitated particles was determined by deducting the mass of each element in the supernatant from the total mass of that specific element in the mixture. Since both ALN and BG contain phosphorus, the mass of P derived from ALN (as measured using the CN Elemental Analyzer) was subtracted from the total 
mass of $\mathrm{P}$ present in the solid sediments to determine the mass of $\mathrm{P}$ derived from BG. Subsequently, the percentage of each element in the precipitated particles was calculated as a percentage of the total mass of dry precipitates.

Sample preparation for the ICP-OES measurements was carried out by diluting all immersion solutions using $2 \mathrm{v} / \mathrm{v} \%$ nitric acid solutions (both before and after precipitation of the particles). A similar ICP-OES method was used to determine the composition of supernatants at different stages of the immersion process.

\subsection{Powder X-ray diffraction (XRD)}

Powder XRD analysis of precipitated particles was carried out using a PANalytical X'Pert ${ }^{3}$ Powder X-ray diffractometer with $\mathrm{Cu}$ $\mathrm{K} \alpha$ radiation at a voltage of $45 \mathrm{kV}$ and a current of $40 \mathrm{~mA}$. The measurements were performed from $7^{\circ}$ to $47^{\circ}(2 \theta)$ using a step size of $0.05^{\circ}$ and a counting time of $30 \mathrm{~s}$ per step.

\subsection{Solid-state nuclear magnetic resonance (NMR) spectroscopy}

Solid-state NMR spectroscopy was used to study the chemical structure and the precipitation mechanism of hybrid particles. In view of the composition of BG and ALN, phosphorous, carbon, sodium, and proton spectra were collected as described below.

Phosphorous spectra were acquired on a Varian NMR spectrometer operating at a proton frequency of $300 \mathrm{MHz}$. Experiments were performed at a Magic angle spinning (MAS) frequency of $10 \mathrm{kHz}$, which did not produce spinning sidebands in the region of real NMR-signals. Cross-polarization (CP) experiments were performed for qualitative evaluation of different samples to save experimental time. In these experiments, a proton $2.5 \mu \mathrm{s} \pi / 2$ pulse was applied $\left(\nu_{1}=100 \mathrm{kHz}\right)$. The resulting phosphorous signal was acquired using ${ }^{1} \mathrm{H}$ decoupling employing a radiofrequency field (rf-field) strength of $75 \mathrm{kHz}$. The CP contacttime was $1.75 \mathrm{~ms}$. Direct-polarization (DP) measurements were conducted for a quantitative analysis of phosphonate and phosphate fractions in the various samples. The relaxation delay of $300 \mathrm{~s}$ was used after relaxation time measurements, which provided spin-lattice relaxation $\left(T_{1}\right)$ values in the range of 35-60 s. ${ }^{31} \mathrm{P}$ chemical shifts were referenced using the known shifts of ALN as a secondary reference. ${ }^{21}$

Carbon spectra were acquired on a Varian NMR spectrometer operating at a proton frequency of $400 \mathrm{MHz}$. Experiments were performed at a MAS frequency of $15 \mathrm{kHz}$. Again the CP pulse sequence was used at a proton rf-field strength of $91 \mathrm{kHz}$, using a $2.75 \mu$ s proton $\pi / 2$ pulse. The CP contact-time was optimized to $2 \mathrm{~ms}$. $75 \mathrm{kHz}$ decoupling power was used to remove dipole-dipole interactions between carbons and protons. ${ }^{13} \mathrm{C}$ chemical shifts were referenced to the known chemical shifts of adamantane; 29 ppm and 38 ppm for methine and methylene carbons, respectively.

Sodium spectra were recorded on an $850 \mathrm{MHz}$ Varian NMR spectrometer at a MAS frequency of $35 \mathrm{kHz}$. The ${ }^{23} \mathrm{Na}$ signal was obtained by means of single pulse excitation using a $30^{\circ}$ pulse to ensure quantitative evaluation of the spectra. The ${ }^{23} \mathrm{Na}$ radiofrequency field strength of $135 \mathrm{kHz}$ was calibrated using solid
$\mathrm{NaCl}$, which was also used as a secondary reference for the chemical shift.

Proton spectra were acquired on an $850 \mathrm{MHz}$ Varian NMR spectrometer at a MAS frequency of $35 \mathrm{kHz}$. Single Pulse Excitation was employed using a hard $90^{\circ}$ pulse (at an rf-field strength of $100 \mathrm{kHz}$ ). The acquisition time was $50 \mathrm{~ms}$. These experiments were performed at high spinning frequencies and high magnetic field to average homonuclear proton-proton couplings and enhance the spectral resolution.

\subsection{In vitro degradation and release behavior of hybrid particles}

Degradation of hybrid particles and release of their content were evaluated upon immersion in aqueous solutions for up to 14 days. To investigate the effect of $\mathrm{pH}$ on the degradation of the particles, the immersion process was carried out at neutral ( $\mathrm{pH}$ 7.4) or acidic ( $\mathrm{pH}$ 5.5) conditions using HEPES- or MES-buffers, respectively. These two conditions were selected to mimic the local $\mathrm{pH}$ of healthy and inflamed tissues, respectively. The buffer solutions were prepared by dissolving $100 \mathrm{mM}$ of HEPES or MES powder in Milli-Q water and adjusting the $\mathrm{pH}$ using $\mathrm{NaOH}$ solution. Thereafter, $20 \mathrm{mg}$ of hybrid particles were added into $2 \mathrm{~mL}$ Eppendorf tubes. The tubes were filled with $2 \mathrm{~mL}$ of a buffered solution and incubated at $37{ }^{\circ} \mathrm{C}$ on a rotating plate at a rate of $120 \mathrm{rpm}$. At each time point, the tubes were centrifuged at $12000 \mathrm{rpm}$ for 2 min. Afterwards, the solutions were collected for further analysis, fresh solutions were added into the tubes, and the tubes were put back in the incubator until the next time point. After the last time point (day 14), the remaining particles were dried at $65{ }^{\circ} \mathrm{C}$ for $2 \mathrm{~h}$ and their weight was measured using an analytical balance. The elemental composition of the collected solutions was analyzed by means of ICP-OES. The cumulative release of each element ( $\mathrm{Ca}, \mathrm{Na}, \mathrm{P}$ and $\mathrm{Si}$ ) was expressed relative to its original content in the hybrid powder. The expressed values for $\mathrm{P}$ include $\mathrm{P}$ derived from both ALN and BG constituents.

\subsection{Influence of hybrid particles on osteoclastic cells}

To assess the biological effect of the particles on osteoclasts, the effects of different concentrations of the particles $(n=6$ for each concentration) were evaluated using osteoclastic cells derived from a mouse leukaemic monocyte-macrophage (RAW 264.7) cell line.

2.8.1 Cell culture experiments. Dulbecco's Modified Eagle's Medium (Gibco, Germany) supplemented with 10\% fetal calf serum (FCS; Sigma-Aldrich, Germany) and 1\% penicillinstreptomycin was used as cell culture medium. RAW 264.7 cells (Sigma-Aldrich, Germany) were seeded in 48-well plates at a density of $10^{5}$ cells per $\mathrm{mL}$. To stimulate the differentiation of RAW cells into osteoclasts, the cells were incubated with $25 \mathrm{ng} \mathrm{\textrm {mL } ^ { - 1 }}$ of macrophage colony-stimulating factor (murine M-CSF, Biochrom, Germany) for 10 days with a partial medium change at day 3 and 7. After 10 days of incubation, the medium was exchanged with fresh medium containing $25 \mathrm{ng} \mathrm{mL}^{-1}$ of M-CSF and $40 \mathrm{ng} \mathrm{mL}^{-1}$ of receptor activator of the NF kappa-B 
ligand (murine RANKL, Biochrom, Germany). On day 14, $20 \mu \mathrm{g}$ of hybrid particles (autoclaved at $121{ }^{\circ} \mathrm{C}$ for $15 \mathrm{~min}$ in a Tuttnauer 2840EL benchtop autoclave) were dispersed in $20 \mathrm{~mL}$ of cell culture medium through 5 min of sonication in an ultrasonication bath. Based on previous studies, ${ }^{22-24}$ a concentration of $100 \mu \mathrm{g} \mathrm{mL}{ }^{-1}$ was used for pure ALN or BG particles as control, since BG is not cytotoxic at this concentration whereas ALN induces anti-osteoclastic effects in vitro at this concentration. Accordingly, different concentrations of hybrid particles were prepared (100, 10 and $\left.1 \mu \mathrm{g} \mathrm{mL}{ }^{-1}\right)$ to determine their effects on osteoclastic cells as a function of their concentration. Thereafter, the particle-free medium was removed from the differentiated osteoclasts and fresh medium containing the particles was added to each well. Cells cultured on polystyrene (PS) well plates in the medium without particles were also considered as controls. After $72 \mathrm{~h}$ of incubation, cell function was analyzed using a range of assays as described below.

2.8.2 Cell viability. The viability of cultured cells was quantified by means of water-soluble tetrazolium salt (WST-8) measurements using a cell counting kit-8 (CCK-8, SigmaAldrich, Germany). The medium was removed from each well and the cells were washed with phosphate buffered saline (PBS). Fresh medium containing $1 \mathrm{v} / \mathrm{v} \%$ of the WST- 8 reagent was added into the wells. After $2 \mathrm{~h}$ of incubation, the solutions were transferred into cuvettes and the absorbance was measured at $450 \mathrm{~nm}$ wavelength using a spectrometer (Specord 40, Analytic Jena, Germany). Values were expressed as percentages relative to the PS control (100\%).

2.8.3 Cell proliferation. The amount of cultured cells was indirectly quantified using a lactic dehydrogenase (LDH) based in vitro toxicology assay kit (Sigma-Aldrich, Germany). The medium was removed from each well and the cells were washed with PBS. The lysis buffer was added on the samples and left in a shaking incubator at $37{ }^{\circ} \mathrm{C}$ for $30 \mathrm{~min}$. Thereafter, the lysates were collected in Eppendorf tubes and centrifuged for $5 \mathrm{~min}$ at $2000 \mathrm{rpm}$. Afterward, $140 \mu \mathrm{L}$ of the supernatants and $60 \mu \mathrm{L}$ of the assay solution (1/3 substrate solution, $1 / 3$ dye solution and $1 / 3$ cofactor solution) were mixed in each cuvette. After $30 \mathrm{~min}$ of incubation, the reaction was stopped by adding $300 \mu \mathrm{L}$ of $1 \mathrm{M} \mathrm{HCl}$ to each cuvette. Finally, $500 \mu \mathrm{L}$ of distilled water were added to each cuvette and the absorbance signals were measured at $490 \mathrm{~nm}$ and $690 \mathrm{~nm}$ (reference) wavelengths using a spectrometer (Specord 40, Analytic Jena, Germany). Values were expressed as percentages relative to the PS control (100\%).

2.8.4 Osteoclastic enzyme activity. The osteoclastic activity of cultured cells was quantified by measuring the tartrateresistant acid phosphatase (TRAP) activity of cells using a TRAP kit (Sigma-Aldrich, Germany). The medium was removed from each well and the cells were washed with PBS. The lysis buffer was added on the samples and left in a shaking incubator at $37{ }^{\circ} \mathrm{C}$ for $30 \mathrm{~min} .50 \mu \mathrm{L}$ lysate of each sample were pipetted in a 96-well plate and $150 \mu \mathrm{L}$ of the substrate buffer $(100 \mathrm{mM}$ NaAcetate, $50 \mathrm{mM}$ NaTartrate and $7.6 \mathrm{mM}$-nitrophenylphosphate; complete buffer $\mathrm{pH}=6.1$ ) were added to each sample. The well plate was incubated in the dark for $4.5 \mathrm{~h}$. Thereafter, the reaction was stopped by adding $50 \mu \mathrm{L}$ of $3 \mathrm{M}$
$\mathrm{NaOH}$ solution to each well. At last, the absorbance was measured at $405 \mathrm{~nm}$ wavelength using a spectrometer (Specord 40, Analytic Jena, Germany).

2.8.5 Expression of vascular endothelial growth factor (VEGF). VEGF is an important growth factor in the bone regeneration process that can be expressed by both osteoclastic and osteoblastic cells. ${ }^{25,26}$ Therefore, the amount of VEGF expressed by osteoclastic cells cultured in the presence of the hybrid particles was quantified using a RayBio ${ }^{\mathbb{R}}$ Mouse VEGF ELISA kit (RayBiotech Inc., USA). The assay was performed according to the manufacturer's guideline. Briefly, the collected medium from each well was added into different wells of an antibody-coated 96-well plate. Thereafter, the plate was incubated for $2.5 \mathrm{~h}$ at room temperature, which was followed by the addition of other assay reagents according to the manufacturer's guideline. Finally, the absorbance was measured at $450 \mathrm{~nm}$ wavelength using a microplate reader (PHOmo, anthos Mikrosysteme $\mathrm{GmbH}$, Germany). Values were expressed as percentages relative to the PS control (100\%).

\subsubsection{Morphological analysis}

Actin/nucleus staining. The medium was removed from each well and the cells were washed with a solution of $1 \%$ bovine serum albumin (BSA) in PBS solution (BSA/PBS). Thereafter, a fixing solution (3.7\% paraformaldehyde in PBS) was added to the samples for $15 \mathrm{~min}$. The fixing solution was then removed and samples were washed with PBS/BSA for three times, each time for 5 minutes. Thereafter, cells were permeabilized with a buffer $(0.1 \%$ Triton-X in PBS) for $5 \mathrm{~min}$. The buffer was removed from each well and the samples were stained with rhodamine phalloidin $\left(8 \mu \mathrm{L} \mathrm{mL}^{-1}\right.$ solutions in PBS/BSA; Thermo Fisher Scientific, USA) for $1 \mathrm{~h}$ in the dark to stain F-actin. Thereafter, cells were washed with PBS/BSA for two times, each time for 5 minutes. Next, cell nuclei were stained with $4^{\prime}$,6-diamidino-2-phenylindole (DAPI, $1 \mu \mathrm{L} \mathrm{mL}^{-1}$ solutions in PBS/BSA, Thermo Fisher Scientific, USA) for $5 \mathrm{~min}$. Finally, cells were washed once with PBS/BSA for 5 min and kept in PBS for microscopic analysis.

TRAP staining. The medium was removed from each well and the cells were washed with PBS. Thereafter, cells were fixed with a fixing solution of $4 \%$ paraformaldehyde in a citrate-acetone solution for $5 \mathrm{~min}$. The fixing solution was removed and cells were washed with PBS. The staining solution (2\% SodiumGarnet solution, $1 \%$ naphtol, $4 \%$ acetate, and $2 \%$ tartrate in water) was added to the cells and left for $2 \mathrm{~h}$ in the dark at $37{ }^{\circ} \mathrm{C}$. The staining solution was removed and cells were washed with distilled water. Finally, the well plate was air-dried for microscopic analysis.

\subsection{Influence of hybrid particles on regeneration of osteoporotic bone}

To assess the influence of hybrid particles on the regeneration of osteoporotic bone defects in vivo, HP1-7 and HP2-7 hybrid particles were selected for implantation into defects created in the femoral condyles of osteoporotic rats. In these experiments, pure BG particles were used as positive control. 
2.9.1 Preparation of hybrid particles for in vivo implantation. Particles were sterilized at $121{ }^{\circ} \mathrm{C}$ for 15 min using a Tuttnauer 2840EL benchtop autoclave. To improve surgical handling and minimize potential leakage of the particles from the bone defects upon implantation, injectable cohesive pastes were prepared by mixing the particles with an aqueous solution of sodium hyaluronate $\left(26 \mathrm{mg} \mathrm{mL} \mathrm{m}^{-1}\right)$. All pastes were composed of a particle/solution $(\mathrm{g} / \mathrm{mL})$ ratio of 0.75 . The pastes were prepared one day prior to the implantation, transferred to $1 \mathrm{~mL}$ sterile syringes, and kept at $4{ }^{\circ} \mathrm{C}$ overnight.

2.9.2 Surgical procedure. A total number of 12 male Wistar rats (12-weeks old, weight of $\sim 250 \mathrm{~g}$ ) was used for the in vivo study. The study protocol was reviewed and approved by the Experimental Animal Committee of the Radboud University (RU-DEC 2015-0036-004) and national guidelines regarding care and use of laboratory animals were followed. First, the rats were acclimatized for 10 days and randomly housed in pairs using standard macrolon type III cages with sawdust as bedding material. The animals were fed with standard rodent chow and bottled tap water ad libitum. The housing room was kept under standard laboratory conditions (light-dark cycle: $12: 12 \mathrm{~h}$, temperature: $20-22{ }^{\circ} \mathrm{C}$, relative humidity: $45-55 \%$ ). After acclimatization, the animals underwent orchidectomy (ORX) surgery to induce an osteoporotic bone condition as described previously, ${ }^{27}$ and had free access to water and low calcium pelleted chow $(0.01 \% \mathrm{Ca}$ and $0.77 \% \mathrm{P}$; ssniff Spezialdiäten $\mathrm{GmbH}$, Soest, Germany). After 6 weeks, osteoporotic conditions in the femoral condyle trabecular bone of the animals were confirmed using an in vivo micro-CT imaging system (Inveon; Siemens Medical Solutions, Knoxville, TN). ${ }^{27}$ Thereafter, bilateral frontal femoral condyle bone defects were made ( $n=8$ per experimental group) and the particulate pastes were injected in the left or right femur of each animal under inhalation anesthesia ( $2 \%$ Isoflurane ${ }^{\circledR}$ by volume) in a randomized manner (Table S1, ESI $\dagger$ ). To perform the surgery, the rats were immobilized supine with the knee joint in a maximally flexed position and the hind limbs were shaved, washed and disinfected with povidone iodine (10\%). After exposure of the knee joint, a $1 \mathrm{~mm}$ pilot hole was drilled and the defect was gradually widened using various drills of increasing size by means of a surgical motor (Elcomed 100, W\&H Dentalwerk Burmoos, Austria) at low rotational drilling speed (800 rpm) and continuous external cooling with saline solution, until a cylindrical defect of $2.5 \mathrm{~mm}$ in diameter and $5 \mathrm{~mm}$ in depth was created. The surgery was carried out in both legs of the animals and one defect was created in each femoral condyle. Thereafter, the pastes were injected into the defects using $1 \mathrm{~mL}$ disposable syringes and the wounds were closed with metallic wound clips (Becton Dickinson, Franklin Lakes, NJ). For pain control, Temgesic ${ }^{\circledR}\left(0.02 \mathrm{mg} \mathrm{kg}^{-1}\right)$ and Rimadyl ${ }^{\circledR}\left(5.0 \mathrm{mg} \mathrm{kg}^{-1}\right)$ were used for 2 days postoperatively. During the implantation period, the rats were fed with the low calcium diet.

2.9.3 Explantation and histological processing. Animals were euthanized by $\mathrm{CO}_{2}$ suffocation after 8 weeks, after which the femoral condyles were carefully removed, cleaned from adhering tissues, and then immediately fixed in neutral buffered formaldehyde for 2 days. Thereafter, the samples were placed in $70 \%$ ethanol solutions, dehydrated in graded series of ethanol solutions (70\% to $100 \%)$ and embedded in poly(methylmethacrylate) (pMMA). After the PMMA embedding procedure, non-decalcified $\sim 10 \mu \mathrm{m}$-thick sections were made cross-sectional perpendicular to the longitudinal axis of the implanted material ( $\geq 3$ sections per specimen) using a modified sawing microtome method ${ }^{28}$ and subsequently stained with methylene blue and basic fuchsin.

2.9.4 Histomorphometrical analysis. Histomorphometrical analysis of stained sections was performed using ImageJ software. The bone area (\%) inside the original bone defects (a circular region of interest of $2.5 \mathrm{~mm}$ in diameter) was quantified in each image. The measurements were performed on three histological sections per femoral condyle. Representative images were color balanced using ImageJ software for better visualization.

\subsection{Statistics}

All values were presented as average \pm standard deviation. The statistical tests were carried out using GraphPad Prism ${ }^{\circledR}$ software. A two-way ANOVA with Tukey's multiple comparisons test was used for statistical analysis of the in vitro tests. Histomorphometrical results were statistically evaluated using a one-way ANOVA test, followed by Tukey's multiple comparisons test. In all tests, the significance threshold was set at $P<0.05$.

\section{Results and discussion}

Previous investigations ${ }^{18,29,30}$ revealed strong interactions between bisphosphonate molecules and BG particles (Fig. S1, ESI $\dagger$ ). To explore the feasibility of exploiting these interactions for the synthesis of hybrid particles, we immersed the BG particles in aqueous solutions containing a high concentration of dissolved ALN (100 mM). BG particles rapidly shrank upon immersion in ALN solutions, and precipitates were formed within 3 days of incubation. However, immersion of BG particles in ALN-free solutions resulted into sedimentation of particles without visual changes during 3 days of incubation. To unravel the chemical nature of these precipitates, we immersed different amounts of BG particles in ALN solutions at different $\mathrm{pH}$ values, and studied the physicochemical properties of resulting precipitates using SEM, TEM, EDX, XRD, solid-state NMR and elemental analysis.

\subsection{Morphology, composition and structure}

Fig. 1 shows SEM images of hybrid particles formed at different immersion conditions. The morphology of the precipitated particles varied depending on the respective $\mathrm{Ca}_{\mathrm{BG}} / \mathrm{ALN}$ ratio (R). While spherulitic particulate clusters were formed at a $\mathrm{Ca}_{\mathrm{BG}} / \mathrm{ALN}$ ratio of 0.5 (Fig. $1 \mathrm{~A}$ and $\mathrm{D}$ ), discrete needle-like microparticles were formed at ratios of 1 and 2 (Fig. 1B, C, $\mathrm{E}$, and F). Importantly, particles synthesized at a ratio of 2 contained unreacted BG residues as confirmed by EDX mapping (Fig. S2, ESI $\dagger$ ). The size and morphology of precipitated particles 

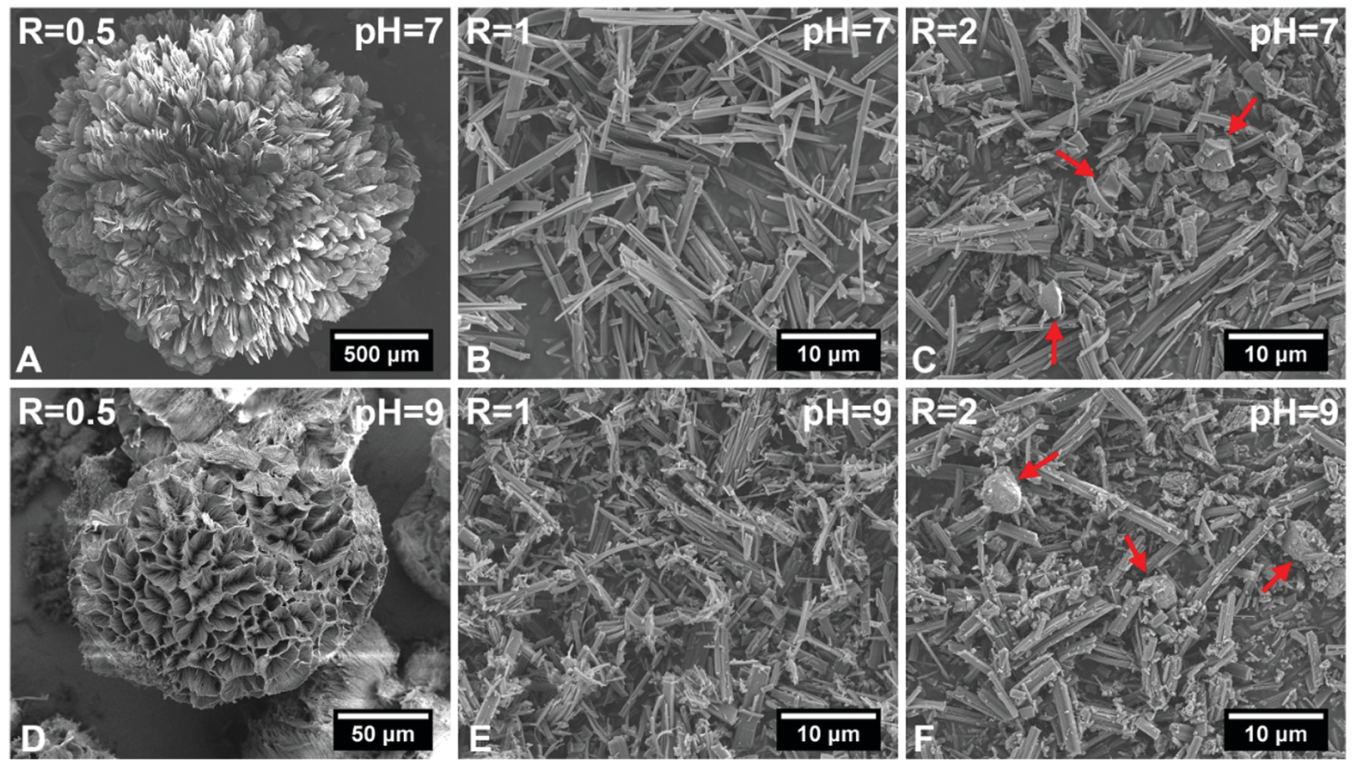

Fig. 1 Scanning electron micrographs of hybrid particles precipitated at different $\mathrm{Ca}_{\mathrm{BG}} / \mathrm{ALN}$ ratios $(R)$ and $\mathrm{pH}$ values after 3 days of incubation at $37^{\circ} \mathrm{C}$. Red arrows indicate bioactive glass residues.

were also affected by the initial $\mathrm{pH}$ of the ALN solution. At a fixed $\mathrm{Ca}_{\mathrm{BG}} / \mathrm{ALN}$ ratio of 0.5 , the precipitated clusters revealed a spherulitic structure $(\sim 2 \mathrm{~mm}$ in diameter) composed of nanosheets or honeycomb-like morphologies $(\sim 0.1 \mathrm{~mm}$ in diameter $)$ composed of entangled nanofibers (Fig. 2) when prepared at $\mathrm{pH} 7$ or 9 , respectively. In general, at a basic $\mathrm{pH}$ of 9 , smaller particles were formed than at a neutral $\mathrm{pH}$ of 7 . For example, at a $\mathrm{Ca}_{\mathrm{BG}} / \mathrm{ALN}$ ratio of 1 , the length of needle-like microparticles was about $9 \pm 5 \mu \mathrm{m}$ or $4 \pm 3 \mu \mathrm{m}$ when prepared at $\mathrm{pH} 7$ or 9 , respectively. However, the shape of the precipitated particles did not depend on the $\mathrm{pH}$ at $\mathrm{Ca}_{\mathrm{BG}} / \mathrm{ALN}$ ratios of 1 and 2. Importantly, when ALN solutions were acidic ( $\mathrm{pH} 5)$, the precipitation of hybrid particles was
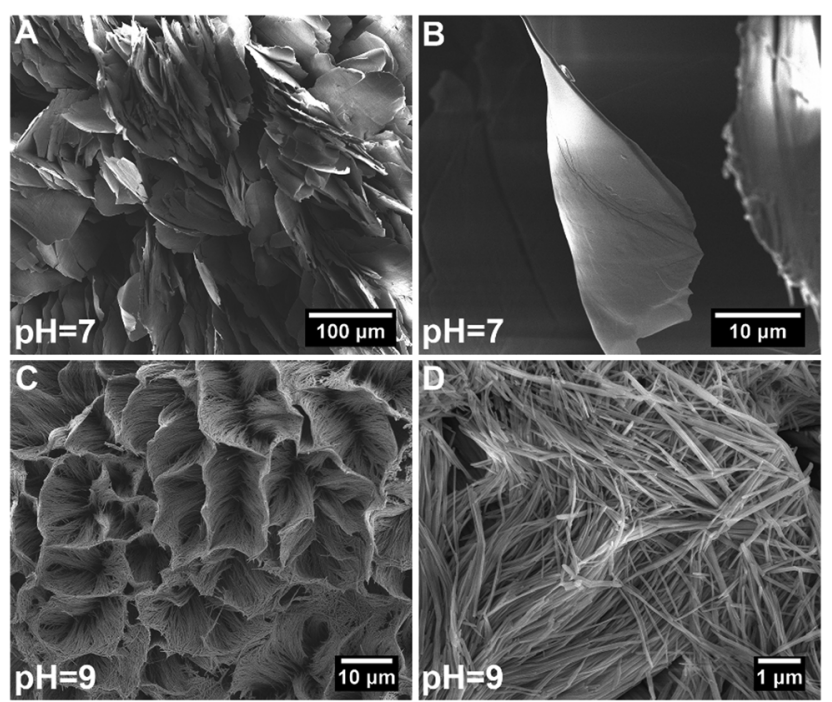

Fig. 2 High magnification scanning electron micrographs of hybrid particles precipitated at a $\mathrm{Ca}_{\mathrm{BG}} / \mathrm{ALN}$ ratio of 0.5 and $\mathrm{a} \mathrm{pH}$ of 7 ( $\mathrm{A}$ and $\mathrm{B}$ ) or 9 (C and D). inhibited due to the protonation of bisphosphonate groups at acidic conditions, reducing their binding affinity for BG surfaces.

The multiple morphologies observed for these hybrid particles resemble the morphological variability as observed in natural structures (e.g. diatoms) where self-assembly occurs between inorganic ions and organic molecules. ${ }^{31}$ Indeed, similar processes have also been studied to enable rational design of precipitating microstructures such as carbonate-silica co-precipitates by controlling reaction conditions such as ionic concentration and solution $\mathrm{pH}^{32,33}$

Variation of the immersion conditions allowed tuning of both the morphology of the precipitated hybrid particles as well as their chemical composition (Table S2, ESI $\dagger$ ). While hybrid particles formed at $\mathrm{Ca}_{\mathrm{BG}} / \mathrm{ALN}$ ratios of 0.5 or 1 contained $\sim 55-70 \mathrm{wt} \%$ of ALN, the ALN content of particles was significantly lowered at a $\mathrm{Ca}_{\mathrm{BG}} / \mathrm{ALN}$ ratio of 2 . At this ratio, the particles also contained higher amounts of $\mathrm{Si}$ and $\mathrm{P}$ (not derived from ALN; see Materials and methods) which can be partially attributed to BG residues. Due to the compositional similarity of samples prepared at $\mathrm{pH} 7$ or 9 , further investigations were focused on hybrid particles formed using ALN solutions at a pH of 7.

We used EDX elemental mapping combined with STEM imaging to determine the elemental distribution within single hybrid particles, which revealed a uniform distribution of elements throughout each particle (Fig. 3A). To assess the crystallinity of hybrid particles, we collected the XRD patterns of various particles types (Fig. 3B). The XRD spectra indicated that the ALN powder was highly crystalline, whereas the BG particles were fully amorphous. Interestingly, the hybrid particles revealed crystalline structures that depended on the $\mathrm{Ca}_{\mathrm{BG}} / \mathrm{ALN}$ ratio used during immersion. The particles precipitated at a ratio of 2 were less crystalline as compared to particles containing lower amounts of BG (prepared at ratios of 0.5 and 1). 

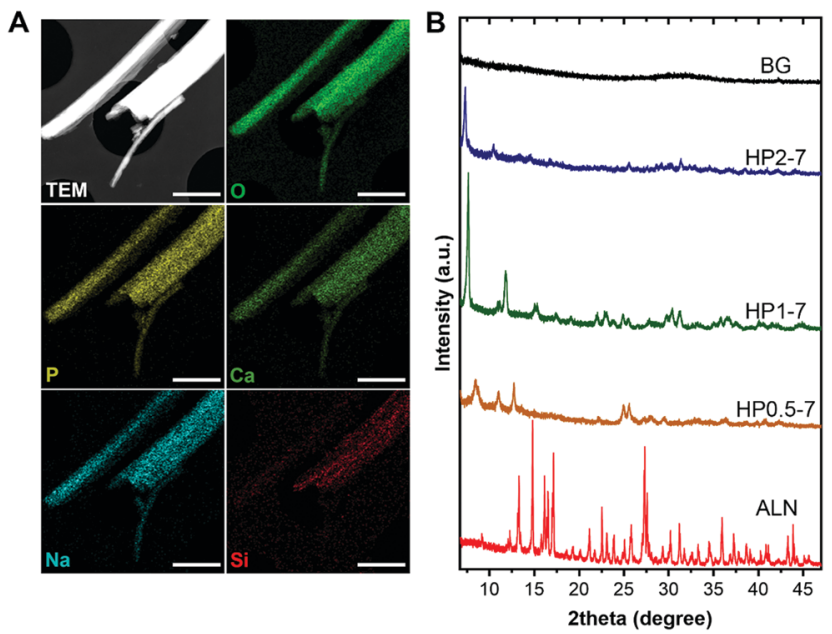

Fig. 3 (A) Scanning TEM image and EDX elemental maps of single HP1-7 particles. (B) Powder XRD spectra of different particle types. Scale bars in images correspond to $1 \mu \mathrm{m}$.

Nevertheless, XRD peaks could not be identified using available crystallographic databases and literature, indicating the formation of novel crystalline phases that were not reported before to the best of our knowledge. Similar to novel metal-organic frameworks, ${ }^{34}$ structural determination of these hybrid particles was challenging. Our attempts to use single-crystal XRD and electron diffraction techniques were not successful due to the small size and electron-beam sensitivity of the hybrid particles, respectively.
Therefore, we used solid-state NMR spectroscopy to gain fundamental understanding of the chemical structure of these hybrid particles (Fig. 4). As shown in Fig. 4A, the ${ }^{13} \mathrm{C}$ spectra of hybrid particles showed pronounced peak broadening and shifts as compared to the peaks of pure ALN, indicating that hybrid particles were less crystalline and contain coordination complexes, respectively. ${ }^{21,35-37}$ The ${ }^{13} \mathrm{C}$ spectrum of HP0.5-7 consisted of four broad signals. In this sample, the largest peak shift $(\Delta \delta=4.6 \mathrm{ppm})$ occurred for the peak at $\sim 72 \mathrm{ppm}$ corresponding to the carbon closest to the phosphonate groups of ALN (see Fig. S3, ESI $\dagger$ for the peak assignment). The two peaks at $\sim 24$ and $\sim 32 \mathrm{ppm}$ corresponded to the $\mathrm{CH}_{2}$ groups and shifted $3.2 \mathrm{ppm}$ downfield, suggesting a large conformational change for ALN molecules. ${ }^{37}$ The smallest shift was observed for the peak located at $\sim 40 \mathrm{ppm}(\Delta \delta=-0.9 \mathrm{ppm})$, indicating that the amine-linked $\mathrm{CH}_{2}$ group was affected least. Interestingly, by increasing the $\mathrm{Ca}_{\mathrm{BG}} / \mathrm{ALN}$ ratio, the ${ }^{13} \mathrm{C}$ spectra became narrower and revealed different features. Particularly, for HP1-7 and HP2-7, the amine-linked $\mathrm{CH}_{2}$ signal showed a larger downfield shift ( $\Delta \delta \approx-4 \mathrm{ppm}$ ) as compared to HP0.5-7, indicating that the amine group also participated in the complex formation when higher $\mathrm{Ca}_{\mathrm{BG}} / \mathrm{ALN}$ ratios were used. Similar trends were observed in the ${ }^{31} \mathrm{P}$ spectra (Fig. $4 \mathrm{~B}$ ) of the hybrid particles. The ${ }^{31} \mathrm{P}$ spectrum of HP0.5-7 showed a broad featureless peak positioned at $20 \mathrm{ppm}$, corresponding to the presence of a variation in the microenvironments around the phosphonate groups at this composition. The ${ }^{31} \mathrm{P}$ spectrum of HP1-7 exhibited a narrower peak, shifted upfield to $17.8 \mathrm{ppm}$, corresponding to a more homogeneous microenvironment
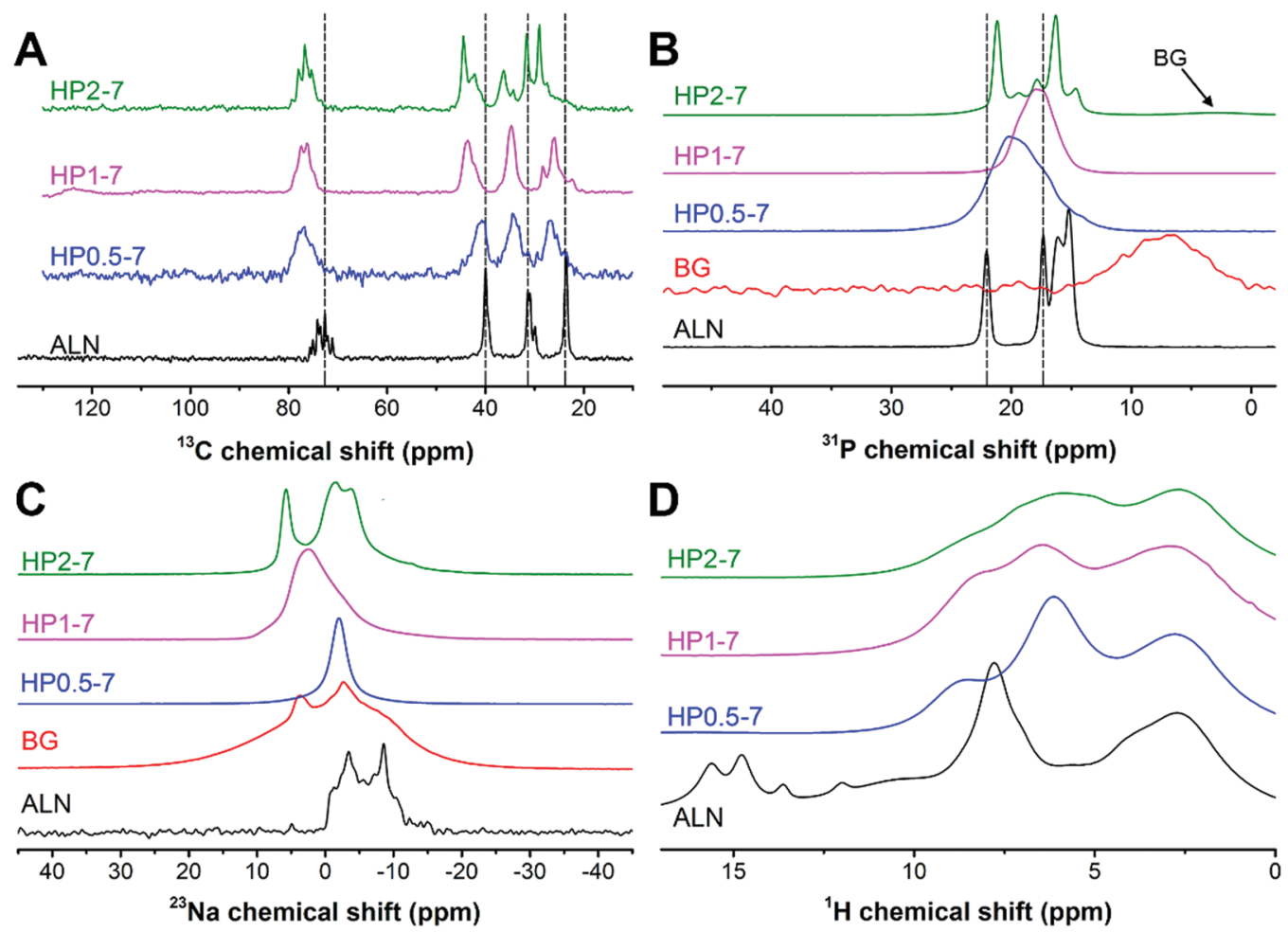

Fig. 4 Solid-state CP-MAS NMR spectra of different types of hybrid particles. 
surrounding the ALN molecules. Moreover, the ${ }^{31} \mathrm{P}$ of $\mathrm{HP} 2-7$ displayed two intense narrow peaks, which suggest the presence of well-ordered domains at this composition. These sharp peaks resembled the sharp peaks present in the ${ }^{31} \mathrm{P}$ spectrum of pure ALN, but displayed a shift which might be caused by complexation with $\mathrm{Ca}^{2+} \cdot 35,38$ Importantly, this spectrum also revealed the existence of a signal from residual BG, which is in agreement with our previous SEM observations. Nevertheless, the BG signal showed a slight upfield shift which indicates that the microenvironment surrounding BG residues in the HP2-7 sample was different from the one in pure BG sample (Fig. S4, $\mathrm{ESI} \dagger)$. Integration of phosphonate (10 to $27 \mathrm{ppm})$ and phosphate $(-2$ to $9 \mathrm{ppm})$ regions of ${ }^{31} \mathrm{P}$ DP spectra of $\mathrm{HP} 2-7$ indicated that $\sim 96 \%$ of all phosphorous in this sample was derived from ALN molecules, while the remaining phosphorus (4\%) was attributed to $\mathrm{BG}$ residues.

As shown in Fig. 4C, the ${ }^{23} \mathrm{Na}$ spectrum of ALN displays a clear second-order quadrupolar pattern from a single Na site in a crystalline material $\left(\delta_{\text {iso }}=0.64 \mathrm{ppm}, e^{2} q Q / h=3.62 \mathrm{MHz}\right.$, $\eta=0.33)$. The HP0.5-7 sample displays a fairly narrow ${ }^{23} \mathrm{Na}$ resonance at around $0 \mathrm{ppm}$ which is likely caused by $\mathrm{Na}$ in an octahedral oxygen coordination (e.g. coordinated by residual water molecules). The HP1-7 particles contained a larger variety of $\mathrm{Na}$ microenvironments as compared to HP0.5-7 and pure ALN. Finally, the HP2-7 sample displayed two ${ }^{23} \mathrm{Na}$ resonances in relatively well-defined environments, a narrow peak at $\sim 6 \mathrm{ppm}$ and a line displaying a fairly well-defined second-order quadrupolar interaction $\left(\delta_{\text {iso }}=1.7 \mathrm{ppm}, e^{2} q Q / h=\right.$ $3.13 \mathrm{MHz}, \eta=0.27)$. In analogy to the ${ }^{31} \mathrm{P}$ spectra this is somewhat similar but certainly not identical to the ALN resonance.

Finally, the ${ }^{1} \mathrm{H}$ spectrum of pure ALN displayed several low field signals $\left(\delta_{\mathrm{H}}>10 \mathrm{ppm}\right)$ corresponding to the phosphonate groups (Fig. 4D). These signals were absent in the spectra of all hybrid particles, corresponding to deprotonation of phosphonate groups and a high degree of coordination complex formation in these samples. ${ }^{35,39}$

Overall, the presented results confirm that hybrid particles were formed with tunable morphology, composition and structure through a simple immersion strategy. Importantly, these results indicate: (i) formation of ALN-cation coordination complexes within the hybrid particles and (ii) a strong dependence of the chemical structure of the hybrid particles on the preparation conditions.

\subsection{Precipitation kinetics}

To elucidate the formation mechanism of hybrid particles and the interactions between BG and ALN, we selected HP1-7 particles to study the precipitation kinetics of these hybrid particles at different time points during the immersion process by analyzing the $\mathrm{pH}$ and elemental composition of supernatants as well as and the weight, morphology and chemical structure of the precipitated particles using weight measurements, SEM and NMR spectroscopy (Fig. 5). As shown in Fig. 5A, BG particles rapidly dissolved immediately after their immersion in the ALN solution; within the first minute of immersion, $\sim 20 \mathrm{wt} \%$ of BG particles dissolved causing a $\mathrm{pH}$ rise from 7 to 10 .
Until 200 min of immersion, dissolution of BG particles caused a continuous release of $\mathrm{Ca}, \mathrm{Na}$ and $\mathrm{Si}$ ions into the supernatant, while the $\mathrm{P}$ content of the supernatant remained almost constant (Fig. 5B). After 200 min of immersion, a sharp reduction of the concentrations of $\mathrm{Ca}, \mathrm{Na}$ and $\mathrm{P}$ in the supernatant coincided with a considerable mass gain of the particles (Fig. 5A), corresponding to the formation of precipitates containing these three specific elements. Nevertheless, the Si concentration in the supernatant continued to rise until the major part of the silica of the original BG particles was released ( $\sim 1000 \mathrm{~min})$, revealing that the released Si ions did not play a dominant role in the formation of the precipitates. On the contrary, the maximum Ca content measured in the supernatant ( $\sim 200 \mathrm{~min}$ ) corresponded to only half of the Ca content of the original BG particles, confirming that $\mathrm{Ca}$ ions were actively involved in the precipitation process. Importantly, the mass of particles as well as the $\mathrm{pH}$ and ionic concentrations of the supernatant stabilized after $1000 \mathrm{~min}$, indicating that the reaction reached an equilibrium state. These results were in agreement with the SEM images of the particles (Fig. 5C), which revealed the presence of needle-like microparticles at $200 \mathrm{~min}$ and the formation of precipitates with identical morphology to the final HP1-7 particles (Fig. 1B) after $1000 \mathrm{~min}$ of immersion.

Next, we studied ${ }^{31} \mathrm{P}$ and ${ }^{23} \mathrm{Na}$ NMR spectra of the particles as a function of immersion time. As shown in Fig. 5D, both phosphate and phosphonate signals were already evident at an early stage of the immersion process $(5 \mathrm{~min})$. Over time, the phosphonate fraction increased while the phosphate fraction gradually declined until its complete disappearance after $200 \mathrm{~min}$ (Fig. 5E). These results suggest that the formation of precipitates proceeded by substitution of phosphate groups of BG particles with phosphonate groups of ALN molecules, which is similar to previously reported mechanisms on the interaction of bisphosphonate drugs with calcium phosphate minerals. ${ }^{37,40}$ Considering the constant concentration of $\mathrm{P}$ in the supernatant during the first $200 \mathrm{~min}$ (Fig. 5B), we propose that this reaction occurs by release of $\sim 2$ phosphate groups per ALN substitution. This substitution reaction did not affect the microenvironment of remaining phosphates in BG particles, since the phosphate peak did not shift substantially from its initial position until its disappearance (intensity $<4 \%$ ) from the spectrum at $200 \mathrm{~min}$ (Table S3, ESI $\dagger$ ). Importantly, the phosphonate peak showed a significant change from 100 to 200 min, displaying an abrupt shift and narrowing of the signal. At this time point, significant changes were observed in the ${ }^{23} \mathrm{Na}$ spectrum of the particles (Fig. 5F). Various Na sites were present in the samples up to $200 \mathrm{~min}$, which reduced to a single Na resonance after $200 \mathrm{~min}$. However, this single resonance showed some distribution in its quadrupolar interaction parameters, indicating that the $\mathrm{Na}$ microenvironment varied throughout the hybrid particles.

Overall, these results suggest that the precipitation of the hybrid particles proceeded through the complexation of ALN with $\mathrm{Ca}$ and $\mathrm{Na}$ cations as present in BG particles. This complexation process occurred by means of substitution of phosphate groups in BG particles by ALN molecules, leading to disruption of the BG silicate network and the release of $\mathrm{Si}$, $\mathrm{Ca}$ and $\mathrm{Na}$. 


\section{A}

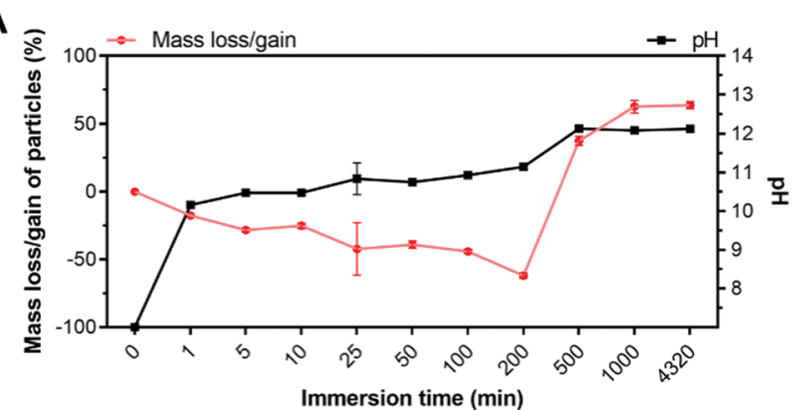

B

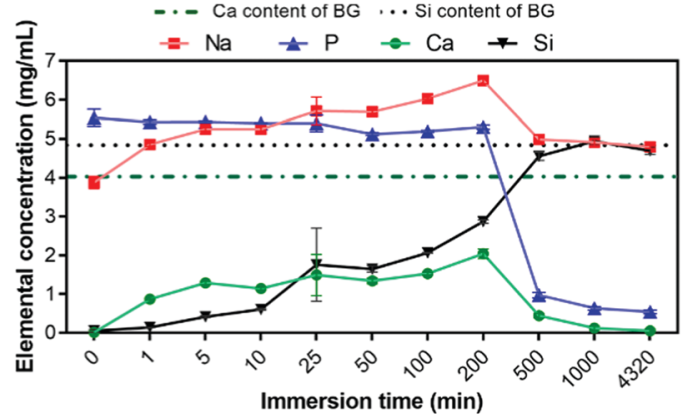

C

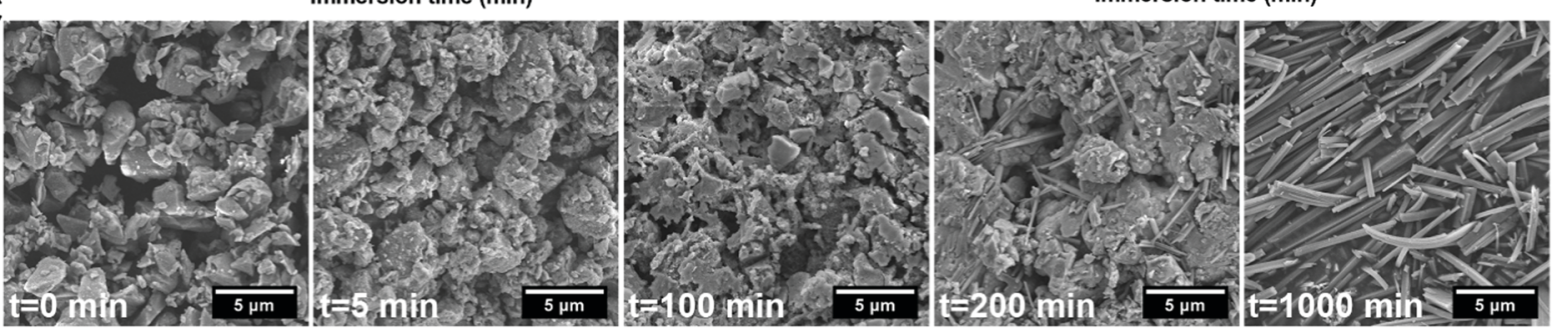

D

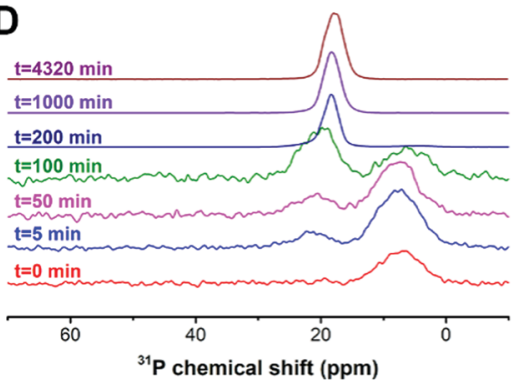

E

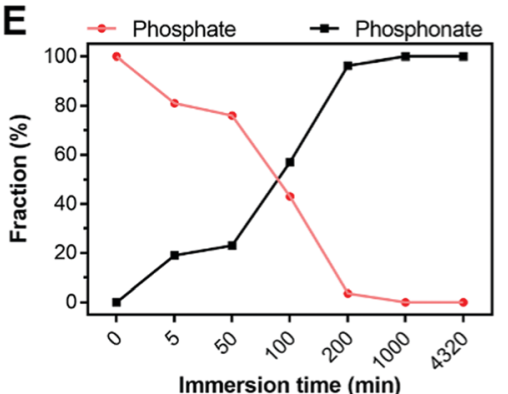

$F$

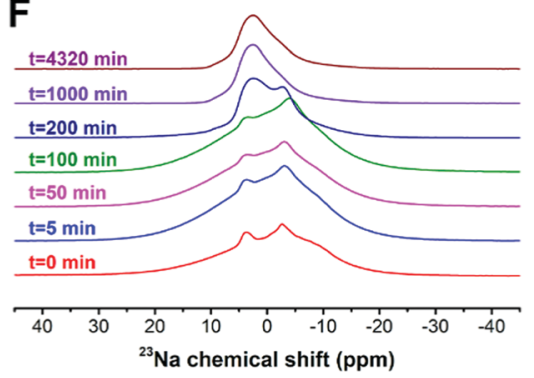

Fig. 5 Precipitation kinetics of HP1-7 particles as a function of immersion time. (A) Mass loss/gain of particles and pH of supernatants. (B) Elemental composition of supernatants during the immersion period. (C) Scanning electron micrographs, (D) solid-state DP ${ }^{31} \mathrm{P} N M R$ spectra, (E) phosphate and phosphonate weight fractions, and (F) solid-state MAS ${ }^{23} \mathrm{Na}$ NMR spectra of particles at various time points. In (A and B), values are presented as average \pm standard deviation for $n=3$ per experimental condition. In (E), values represent the phosphate and phosphonate fractions calculated based on the NMR spectra shown in (D).

The reaction between ALN and BG almost completely disrupted the BG structure after $200 \mathrm{~min}$ of immersion. This disruption was followed by a rapid precipitation and growth of hybrid particles, which stopped after 1000 min of immersion.

\subsection{In vitro degradation and release behavior}

The hybrid particles exhibited a pH- and composition-dependent degradation behavior in aqueous media (Fig. S5, ESI $\dagger$ ). Therefore, to elucidate the degradability of these particles for applications in regenerative medicine, we studied the release of their degradation products in vitro at neutral $\mathrm{pH}$ (7.4) as well as acidic $\mathrm{pH}$ (5.5) to mimic acidosis. ${ }^{41}$ In addition, this acidic testing condition was selected since the interaction of ALN with BG was found to be strongly pH-dependent (see Section 3.1). Fig. 6 shows the cumulative release of various inorganic elements from hybrid particles, expressed as percentage of their original content in the hybrid particles, upon immersion in neutral or acidic solutions for up to 14 days. In general, the particles with a low ALN content (HP2-7) released more calcium than the two other particle types, but tended to retain their sodium content, whereas HP0.5-7 and HP1-7 showed an opposite trend by releasing less calcium but more sodium. At the neutral $\mathrm{pH}, \mathrm{HP} 0.5-7$ and HP1-7 particles showed an initial rapid release of their $\mathrm{P}$ contents which stabilized at $\sim 20 \%$ upon 3 days of immersion, whereas the particles of low ALN content displayed a more gradual $\mathrm{P}$ release. Based on the composition of hybrid particles (Table S2, ESI $\dagger$ ), the P released from HP0.5-7 and HP1-7 particles corresponds almost entirely to ALN, whereas the $\mathrm{P}$ released from the particles of low ALN content is related to a more even mixture of both ALN and BG constituents. Despite the low Si content of HP0.5-7 and HP1-7 particles (Table S2, ESI $\dagger$ ), their Si release was more pronounced, suggesting that the minor trace of $\mathrm{Si}$ was not well integrated in the structure of these particle types. As hypothesized, the acidification of solutions strongly affected the release behavior of the hybrid particles. An enhancement of Ca release was observed for all particle types upon acidification. $\mathrm{Na}$ release from HP0.5-7 and HP1-7 particles was also increased at acid $\mathrm{pH}$, but $\mathrm{Na}$ release from the particles of low ALN content was hardly affected by the acidification, suggesting that $\mathrm{Na}$ played a more dominant role in complex formation in HP0.5-7 and HP1-7. A strong enhancement of $\mathrm{P}$ release upon acidification was only observed for the particles of low ALN content, which is in agreement with our degradation results (Fig. S5, ESI $\dagger$ ). 

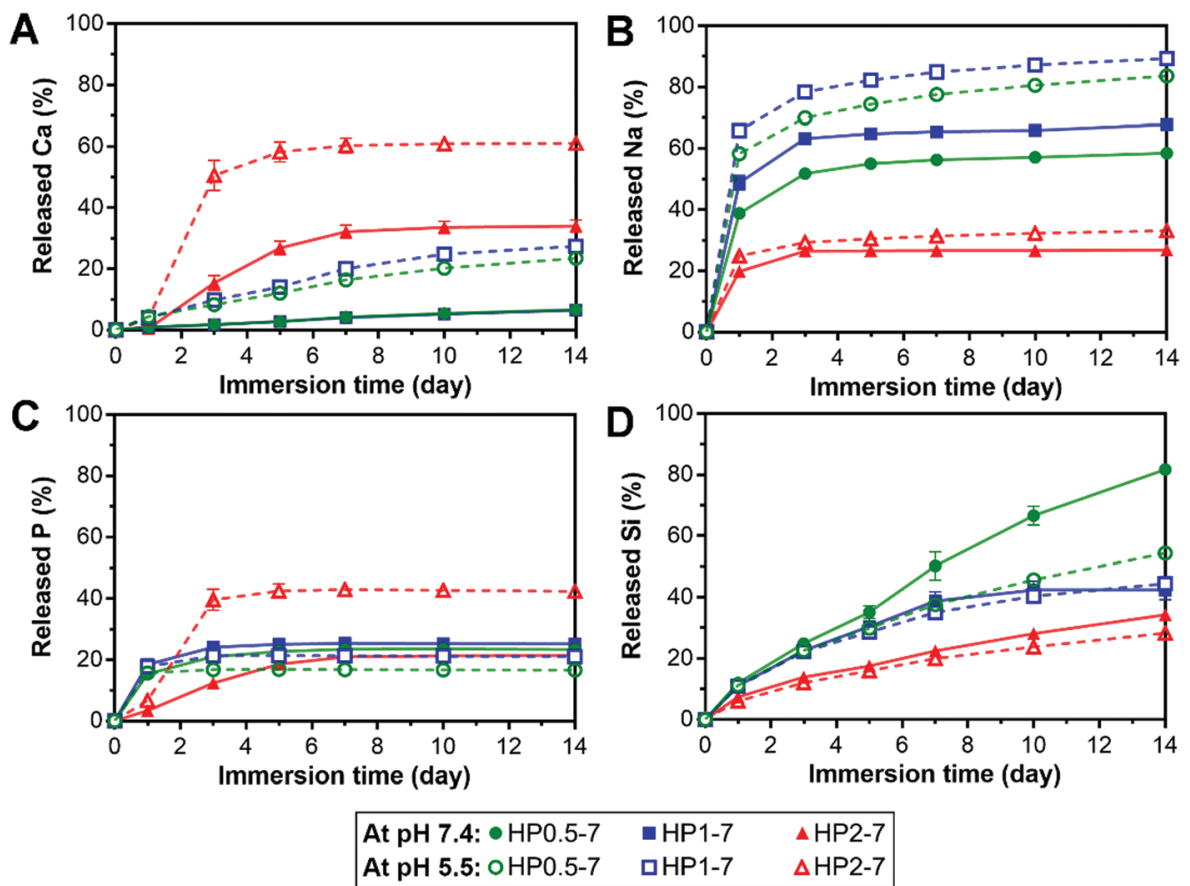

Fig. 6 Cumulative release profiles of different elements from hybrid particles into buffered solutions at acidic (open symbols) or neutral pH (closed symbols). The release of each element was expressed relative to its original content in the hybrid particles. All values are presented as average \pm standard deviation for $n=3$ per experimental condition.

Overall, these results indicate that the hybrid particles are degradable, which is an attractive feature of this novel class of biomaterials for application in bone tissue regeneration, since biomaterials should degrade to allow for replacement by newly formed bone tissue. ${ }^{42}$ In addition, anti-osteoporotic ALN molecules and BG-derived inorganic ions were released in a controllable manner. This controlled release is facilitated by the interactions between both components within the hybrids particles (e.g. through formation of coordination complexes). Inorganic ions are known to affect the regeneration of bone tissue in vivo. ${ }^{43}$ For example, specific concentrations of Ca ions were shown to stimulate proliferation and differentiation of osteoblastic cells and induce mineralization of the extracellular matrix. ${ }^{44}$ In addition, phosphate ions can promote the expression of matrix Gla protein (MGP) which is a key regulator for bone formation. ${ }^{45}$ Furthermore, $\mathrm{Si}$ is an important factor for bone formation which can affect the precipitation of hydroxyapatite. ${ }^{46,47}$ Nevertheless, it should be stressed that the biological effects of ALN and bioinorganic ions depend on their concentration in the extracellular matrix. Moreover, to determine the effectiveness of hybrid particles for the regeneration of osteoporotic bone defects, it is necessary to investigate their biological activity as compared to that of pure ALN and BG particles.

\subsection{Influence of hybrid particles on osteoclastic cell function}

In view of the excessive activity of bone-resorbing osteoclasts in osteoporotic bone, we studied in vitro the capability of the hybrid particles to reduce the activity of osteoclastic cells. To this end, we first selected the HP1-7 particles which contained an intermediate ALN content (Table S2, ESI $\dagger$ ) to evaluate the influence of different concentrations of hybrid particles $(0,1$, 10 and $100 \mu \mathrm{g} \mathrm{mL}{ }^{-1}$ ) on the viability, proliferation, enzymatic activity and VEGF expression of osteoclast-like cells upon $72 \mathrm{~h}$ of in vitro incubation. We measured the viability and proliferation of osteoclastic cells by quantifying the formazan production of living cells and the LDH harvested upon cell lysis using WST-8 and LDH-activity assays, respectively (Fig. 7A). These tests revealed that osteoclast viability and proliferation decreased with increasing concentration of hybrid HP1-7 particles. At a concentration of $100 \mu \mathrm{g} \mathrm{mL}{ }^{-1}$, HP1-7 particles showed the same effect in vitro as pure ALN, whereas BG particles did not affect osteoclast viability and proliferation. We then measured the TRAP-activity of the cells as a key marker for osteoclast activity ${ }^{48,49}$ to assess the effect of hybrid HP1-7 particles on osteoclastic cells (Fig. 7B). No TRAP enzyme activity was detected for osteoclasts cultured in the presence of $100 \mu \mathrm{g} \mathrm{mL} \mathrm{mL}^{-1}$ of HP1-7 particles or pure ALN, while lower concentrations of hybrid particles did not reduce the TRAP activity. After identifying $100 \mu \mathrm{g} \mathrm{mL} \mathrm{mL}^{-1}$ as the most effective antiosteoclastic concentration for HP1-7 particles, we performed similar tests using HP0.5-7 or HP2-7 hybrid particles at the same particle concentration, which showed similar anti-osteoclastic effects (data not shown). These results were in agreement with our microscopic observations performed using actin/nucleus or TRAP staining of the cells (Fig. S6, ESI $\dagger$ ). Importantly, bioactive glasses can release an excessive amount of alkaline ions into cell culture media, resulting in an undesirable $\mathrm{pH}$ increase of their environment, thus affecting cell viability during static culture conditions. ${ }^{50}$ Nevertheless, the BG control $\left(100 \mu \mathrm{g} \mathrm{mL}{ }^{-1}\right)$ did 

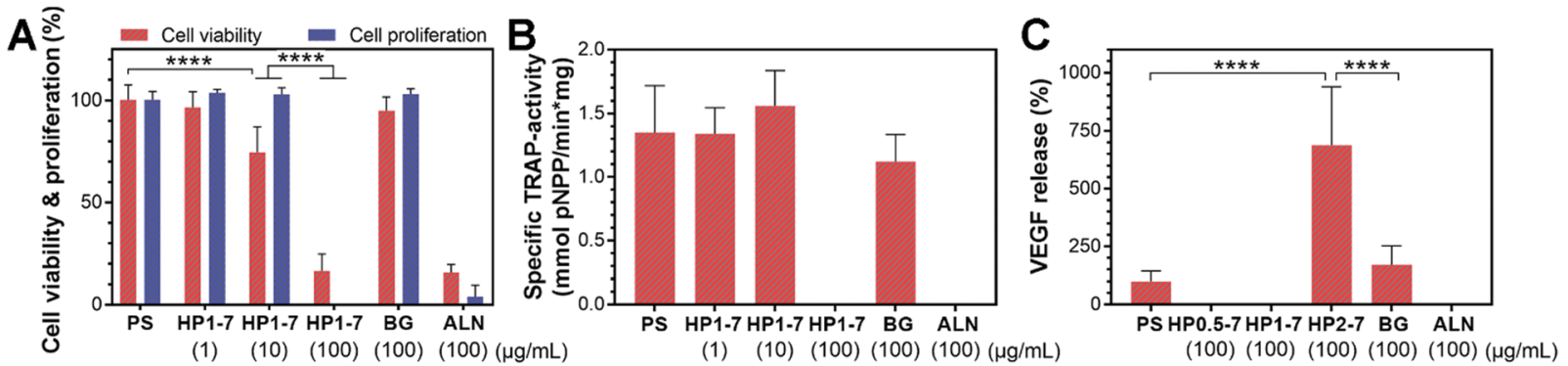

Fig. 7 In vitro effects of hybrid particles on RAW 264.7-derived osteoclastic cells. (A) Viability and proliferation, (B) TRAP-activity, and (C) VEGF expression of cells upon incubation with different materials. Numbers in parentheses indicate the concentrations of particles in cell culture medium. PS, HP, BG, and ALN refer to particle-free polystyrene control, hybrid particles, bioactive glass, and alendronate, respectively.

not affect osteoclastic cells in our experiments, indicating that the anti-osteoclastic effect of the hybrid particles is based on the presence of functional ALN in their composition, and is not caused by a pH change that can occur due to the release of BG constituents.

An important growth factor in the bone regeneration process that can be expressed by osteoclastic and osteoblastic progenitor cells is VEGF. ${ }^{25,26}$ VEGF expression can induce angiogenesis, which is an essential factor for the formation of healthy bone tissue. ${ }^{25}$ Accordingly, we measured the amount of VEGF expressed by the osteoclasts after exposure to hybrid particles of different composition prepared using $\mathrm{Ca}_{\mathrm{BG}} / \mathrm{ALN}$ ratios of 0.5 , 1 or 2 (Fig. 7C). Interestingly, we observed a significant upregulation of VEGF expression when the cells were exposed to HP2-7 particles for $72 \mathrm{~h}$. VEGF expression is usually mediated by hypoxia which activates hypoxia-inducible factor 1 (HIF-1) in cells. ${ }^{51,52}$ HIF-1 is a transcription factor that is composed of inducible $\alpha$ and constitutively expressed $\beta$ subunits. Under hypoxia, the $\alpha$ subunit is stabilized enabling the expression of VEGF. Nevertheless, VEGF expression has also been found to occur under normoxic conditions. For instance, Trebec-Reynolds $e t$ al. ${ }^{26}$ reported that VEGF expression by RAW 264.7-derived osteoclasts can be induced though a non-hypoxic pathway. Consequently, further investigations are needed to determine the pathway through which HP2-7 particles induce VEGF expression in osteoclastic cells.

Lastly, the potential effect of ALN content of hybrid particles on bone-forming osteoblastic cells should also be considered. Our in vitro release experiments (Section 3.3) revealed that the HP1-7 particles release $\sim 20 \%$ of their ALN content during a $72 \mathrm{~h}$ incubation period, which translates to an ALN concentration of $\sim 50 \mu \mathrm{M}$ for a particle concentration of $100 \mu \mathrm{g} \mathrm{mL}^{-1}$ in our cell culture experiments. Garcia-Moreno et al. ${ }^{53}$ studied the effect of different concentrations of ALN $\left(10^{-1}\right.$ to $\left.10^{-12} \mathrm{M}\right)$ on primary osteoblasts in vitro and found no effect on cell viability and proliferation at ALN concentrations of $<100 \mu \mathrm{M}$. Considering the dynamic vs. static nature of in vivo vs. in vitro tests, respectively, we anticipate that ALN would not negatively affect the viability of osteoblasts in vivo. Nevertheless, it should be stressed that these claims can only be substantiated by performing in vivo implantation studies. Therefore, we performed an additional implantation study to investigate the osteocompatibility and bone regenerative capability of selected hybrid particles in osteoporotic rats.

\subsection{Influence of hybrid particles on regeneration of osteoporotic bone}

In view of the strong effects of hybrid HP1-7 and HP2-7 particles on osteoclastic cell function, we selected these two types of hybrid particles for an in vivo implantation study under osteoporotic conditions, while 45S5 BG particles were used as control in view of their well-known osteopromotive capacity. ${ }^{9}$ As shown in Fig. 8A and B, after 8 weeks of implantation of HP1-7 particles in osteoporotic rats, abundant bone formation was observed inside the original defect area without any visible inflammatory response, similar to the control BG group (Fig. 8E and F). However, the defects filled with HP2-7 particles showed low amounts of bone formation and contained material remnants after the implantation period (Fig. 8C and D). As shown in Fig. 8G, quantification of new bone formation inside the original defects indicated that the HP1-7 particles facilitated bone formation at levels similar to 45S5 BG particles, whereas the amount of newly formed bone was much lower upon implantation of HP2-7 particles. Such remarkable difference between the in vivo behavior of HP1-7 and HP2-7 particles can be attributed to the differences between their composition, structure and degradation behavior. For instance, upon implantation of biomaterials, the local $\mathrm{pH}$ of bone tissue drops from $\sim 7.4$ to $\sim 5.5$ due to an inflammatory response. ${ }^{54}$ As described in Section 3.3, such local acidification leads to the release of significantly higher amounts of Ca ions and ALN for HP2-7 particles as compared to HP1-7 particles. As shown in previous studies, ${ }^{44,55,56}$ such high concentrations of $\mathrm{Ca}$ and/ or ALN might be cytotoxic for bone-forming osteoblast cells, thereby impeding in vivo bone regeneration. Interestingly, as shown in the inset of Fig. 8D, we observed macrophage-rich regions near HP2-7 remnants suggesting an inflammatory response caused by these particles. Although HP1-7 and 45S5 BG particles both stimulated the formation of bone tissue, the underlying stimulatory mechanism is expected to be different for both types of particles. While 45S5 BG particles can induce bone formation owing to their apatite-forming ability and osteogenic effects caused by their ionic dissolution products, ${ }^{9,43}$ HP1-7 particles can assist bone regeneration by inhibiting bone 


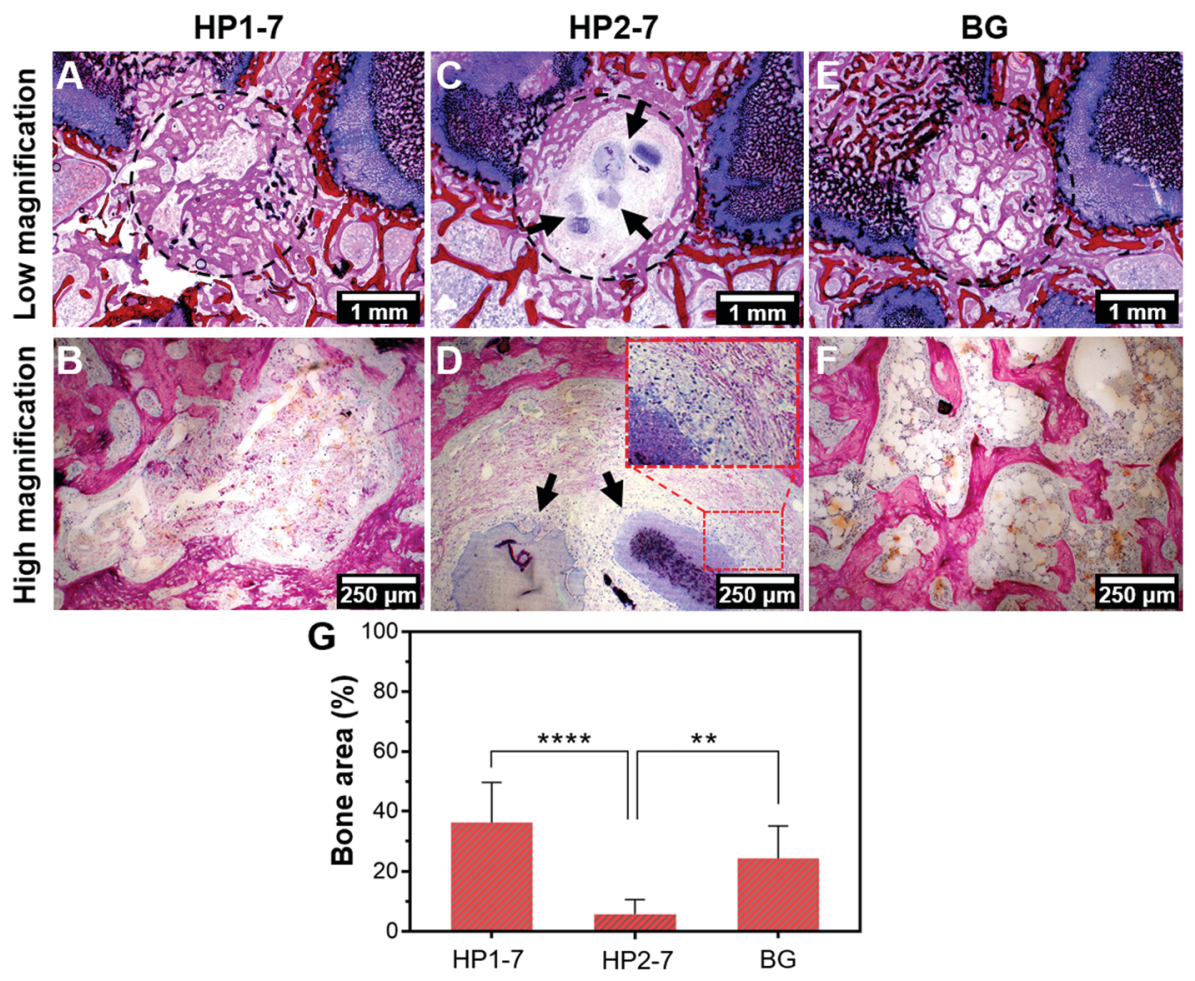

Fig. 8 In vivo evaluation of hybrid particles. (A-F) Representative histological images and (G) quantified bone area (\%) of different experimental groups after 8 weeks of implantation. Circles and arrows in images indicate the original defect area and material remnants, respectively. ${ }^{\star \star}$ and ${ }^{\star \star \star \star}$ indicate $P<0.005$ and $P<0.0001$, respectively.

resorption through the release of ALN and promoting bone formation by releasing inorganic ions with osteogenic efficacy. ${ }^{44}$ Nevertheless, a more detailed in vivo investigation is required to unravel the exact mechanism by which HP1-7 particles are able to support bone formation.

\section{Conclusion}

We have demonstrated the facile preparation of a novel class of hybrid particles of tunable morphology, chemical composition and structure. By immersing 45S5 BG particles in ALN solutions, phosphate ions of BG were substituted by ALN molecules, thereby forming ALN-cation coordination complexes. This synthesis procedure resulted in dissolution of BG particles and precipitation of novel hybrid particles. By varying immersion conditions, the morphology, chemical composition and structure of precipitated hybrid particles could be tuned. The hybrid particles facilitated controlled release of anti-osteoporotic ALN molecules and BG-derived inorganic ions, and displayed a strong anti-osteoclastic effect in vitro. In vivo evaluation of the hybrid particles revealed their strong capacity to facilitate regeneration of bone defects in an osteoporotic rat model. Our findings demonstrated that both in vitro and in vivo effects of the hybrid particles could be tuned by varying the chemical composition and structure of these novel hybrid particles. Consequently, considering this tunability of properties, this novel class of hybrid biomaterials opens up new avenues of research on the design of bone substitutes with specific activity to facilitate regeneration of bone in osteoporotic patients, for instance by applying the same synthetic procedures to BG compositions which contain osteogenic strontium ions to further boost the regeneration of osteoporotic bone defects.

\section{Conflicts of interest}

There are no conflicts to declare.

\section{Acknowledgements}

This study was funded by Netherlands Enterprise Agency through Project No. SHM012014 in the theme IOP Self Healing Materials. Mani Diba would like to thank Prof. John A. Jansen and Dr. Matthew J. Harrington for valuable discussions and suggestions.

\section{References}

1 A. Klibanski, L. Adams-Campbell, T. Bassford, S. N. Blair, S. D. Boden, K. Dickersin, D. R. Gifford, L. Glasse, S. R. Goldring, K. Hruska, S. R. Johnson, L. K. McCauley and W. E. Russell, J. Am. Med. Assoc., 2001, 285, 785-795.

2 O. Johnell and J. A. Kanis, Osteoporosis Int., 2006, 17, 1726-1733. 3 R. A. Perez, S.-J. Seo, J.-E. Won, E.-J. Lee, J.-H. Jang, J. C. Knowles and H.-W. Kim, Mater. Today, 2015, 18, 573-589.

4 D. Arcos, A. R. Boccaccini, M. Bohner, A. Díez-Pérez, M. Epple, E. Gómez-Barrena, A. Herrera, J. A. Planell, L. RodríguezMañas and M. Vallet-Regí, Acta Biomater., 2014, 10, 1793-1805. 
5 D. G. Little, M. Ramachandran and A. Schindeler, J. Bone Jt. Surg., Br. Vol., 2007, 89-B, 425-433.

6 H. Fleisch, Endocr. Rev., 1998, 19, 80-100.

7 S. B. Woo, J. W. Hellstein and J. R. Kalmar, Ann. Intern. Med., 2006, 144, 753-761.

8 J. P. Cattalini, A. R. Boccaccini, S. Lucangioli and V. Mouriño, Tissue Eng., Part B, 2012, 18, 323-340.

9 J. R. Jones, Acta Biomater., 2013, 9, 4457-4486.

10 A. A. El-Rashidy, J. A. Roether, L. Harhaus, U. Kneser and A. R. Boccaccini, Acta Biomater., 2017, 62, 1-28.

11 L. L. Hench, R. J. Splinter, W. C. Allen and T. K. Greenlee, J. Biomed. Mater. Res., 1971, 5, 117-141.

12 A. K. Miri, N. Muja, N. O. Kamranpour, W. C. Lepry, A. R. Boccaccini, S. A. Clarke and S. N. Nazhat, Biomaterials, 2016, 85, 128-141.

13 L. L. Hench and J. M. Polak, Science, 2002, 295, 1014-1017. 14 M. Bosetti and M. Cannas, Biomaterials, 2005, 26, 3873-3879.

15 S. Srisubut, A. Teerakapong, T. Vattraphodes and S. Taweechaisupapong, Oral Surg., Oral Med., Oral Pathol., 2007, 104, e11-e16.

16 X. V. Bui, H. Oudadesse, Y. Le Gal, A. Mostafa, P. Pellen and G. Cathelineau, J. Aust. Ceram. Soc., 2010, 46, 24-28.

17 J. H. Lee, K. M. Lee, S. J. Jang, H. S. Lee and H. R. Baek, Tissue Eng. Regener. Med., 2011, 8, 69-77.

18 K. Rosenquist, S. Airaksinen, S. J. Fraser, K. C. Gordon and A. M. Juppo, Int. J. Pharm., 2013, 452, 102-107.

19 E. Boanini, S. Panseri, F. Arroyo, M. Montesi, K. Rubini, A. Tampieri, C. Covarrubias and A. Bigi, Materials, 2016, 9, 135.

20 S. Ray, R. Acharya, S. Saha, A. Islam, S. Dey, S. K. Nandi, T. K. Mandal, G. Banerjee and J. Chakraborty, RSC Adv., 2016, 6, 89467-89483.

21 M. S. Ironside, M. J. Duer, D. G. Reid and S. Byard, Eur. J. Pharm. Biopharm., 2010, 76, 120-126.

22 R. Detsch, M. Rübner, P. L. Strissel, D. Mohn, E. Strasser, W. J. Stark, R. Strick and A. R. Boccaccini, Nanomedicine, 2016, 11, 1093-1105.

23 R. Detsch, P. Stoor, A. Grünewald, J. A. Roether, N. C. Lindfors and A. R. Boccaccini, J. Biomed. Mater. Res., Part A, 2014, 102, 4055-4061.

24 V. Breuil, F. Cosman, L. Stein, W. Horbert, J. Nieves, V. Shen, R. Lindsay and D. W. Dempster, J. Bone Miner. Res., 1998, 13, 1721-1729.

25 M. Grellier, L. Bordenave and J. Amédée, Trends Biotechnol., 2009, 27, 562-571.

26 D. P. Trebec-Reynolds, I. Voronov, J. N. M. Heersche and M. F. Manolson, J. Cell. Biochem., 2010, 110, 343-351.

27 H. S. Alghamdi, J. J. J. P. van den Beucken and J. A. Jansen, Tissue Eng., Part C, 2014, 20, 493-505.

28 H. B. M. van der Lubbe, C. P. A. T. Klein and K. de Groot, Stain Technol., 1988, 63, 171-176.

29 M. Diba, J. An, S. Schmidt, M. Hembury, D. Ossipov, A. R. Boccaccini and S. C. G. Leeuwenburgh, Macromol. Rapid Commun., 2016, 37, 1952-1959.

30 M. Diba, W. A. Camargo, M. Brindisi, K. Farbod, A. Klymov, S. Schmidt, M. J. Harrington, L. Draghi, A. R. Boccaccini,
J. A. Jansen, J. J. J. P. van den Beucken and S. C. G. Leeuwenburgh, Adv. Funct. Mater., 2017, 27, 1703438.

31 S. Weiner and L. Addadi, J. Mater. Chem., 1997, 7, 689-702. 32 W. L. Noorduin, A. Grinthal, L. Mahadevan and J. Aizenberg, Science, 2013, 340, 832-837.

33 C. N. Kaplan, W. L. Noorduin, L. Li, R. Sadza, L. Folkertsma, J. Aizenberg and L. Mahadevan, Science, 2017, 355, 1395-1399. 34 F. Gandara and T. D. Bennett, IUCrJ, 2014, 1, 563-570.

35 E. Alvarez, A. G. Marquez, T. Devic, N. Steunou, C. Serre, C. Bonhomme, C. Gervais, I. Izquierdo-Barba, M. ValletRegi, D. Laurencin, F. Mauri and P. Horcajada, CrystEngComm, 2013, 15, 9899-9905.

36 G. Grossmann, A. Grossmann, G. Ohms, E. Breuer, R. Chen, G. Golomb, H. Cohen, G. Hägele and R. Classen, Magn. Reson. Chem., 2000, 38, 11-16.

37 S. Mukherjee, Y. Song and E. Oldfield, J. Am. Chem. Soc., 2008, 130, 1264-1273.

38 M. W. G. Lockyer, D. Holland and R. Dupree, J. Non-Cryst. Solids, 1995, 188, 207-219.

39 E. Boanini, P. Torricelli, M. Gazzano, R. Giardino and A. Bigi, Biomaterials, 2008, 29, 790-796.

40 F. Errassifi, S. Sarda, A. Barroug, A. Legrouri, H. Sfihi and C. Rey, J. Colloid Interface Sci., 2014, 420, 101-111.

41 T. R. Arnett, Arch. Biochem. Biophys., 2010, 503, 103-109.

42 K. Rezwan, Q. Z. Chen, J. J. Blaker and A. R. Boccaccini, Biomaterials, 2006, 27, 3413-3431.

43 A. Hoppe, N. S. Güldal and A. R. Boccaccini, Biomaterials, 2011, 32, 2757-2774.

44 S. Maeno, Y. Niki, H. Matsumoto, H. Morioka, T. Yatabe, A. Funayama, Y. Toyama, T. Taguchi and J. Tanaka, Biomaterials, 2005, 26, 4847-4855.

45 M. Julien, S. Khoshniat, A. Lacreusette, M. Gatius, A. Bozec, E. F. Wagner, Y. Wittrant, M. Masson, P. Weiss, L. Beck, D. Magne and J. Guicheux, J. Bone Miner. Res., 2009, 24, 1856-1868.

46 E. M. Carlisle, Calcif. Tissue Int., 1981, 33, 27-34.

47 J. J. M. Damen and J. M. Ten Cate, J. Dent. Res., 1992, 71, 453-457.

48 J. M. Halleen, S. L. Alatalo, H. Suominen, S. Cheng, A. J. Janckila and H. K. Väänänen, J. Bone Miner. Res., 2000, 15, 1337-1345.

49 R. Detsch and A. R. Boccaccini, J. Tissue Eng. Regener. Med., 2015, 9, 1133-1149.

50 F. E. Ciraldo, E. Boccardi, V. Melli, F. Westhauser and A. R. Boccaccini, Acta Biomater., 2018, 75, 3-10.

51 D. Shweiki, A. Itin, D. Soffer and E. Keshet, Nature, 1992, 359, 843-845.

52 M. C. Brahimi-Horn and J. Pouysségur, Biochem. Pharmacol., 2007, 73, 450-457.

53 C. García-Moreno, S. Serrano, M. Nacher, M. Farré, A. Díez, M. L. Mariñoso, J. Carbonell, L. Mellibovsky, X. Nogués, J. Ballester and J. Aubía, Bone, 1998, 22, 233-239.

54 J. B. Park, Biomaterials: An introduction, Plenum Publishing Corporation, 1979.

55 J. Sun, F. Y. Song, W. P. Zhang, B. E. Sexton and L. J. Windsor, Arch. Oral Biol., 2012, 57, 728-736.

56 E. W. H. Bodde, R. S. Z. Kowalski, P. H. M. Spauwen and J. A. Jansen, Tissue Eng., Part A, 2008, 14, 29-39. 